\title{
From Memorized Chunks to Rule Formation: A Study of Adult Chinese Learners of English
}

\author{
Xia Yu \\ Southwest University of Political Science and Law, P. R.C \\ E-mail: sheilayu327@hotmail.com
}

Received: 16-08- 2012

Accepted: 24-09- 2012

Published: 01-01- 2013

doi:10.7575/ijalel.v.2n.1p.98

URL: http://dx.doi.org/10.7575/ijalel.v.2n.1p.98

This research is funded by the Scientific Research Fund for 2011 brought-in talent of Southwest University of Political Science and Law (Approval No: 2011-XZRCXM001).

\begin{abstract}
Recent empirical research on the role of formulaic language appears to support the assumption that memorized chunks serve as a database for learning of the grammar, a process of what Skehan (1998) call 'syntacticization'. This paper examines the possibility of 'syntacticization' without the help of explicit instruction in the case of adult classroom learners. The study reported here investigates the extent to which Chinese tertiary-level learners of English acquire the rule of despite + NP beyond initial memorization of chunks. This is a classroom experiment in which the data were collected from 104 non-English majors in a Chinese university through written elicitation tests. The subjects were randomly assigned to two memorization groups and an instruction group. The results seem to show that the participants in the memorization groups had difficulty inducing rules successfully based on the initial memorization of unanalysed chunks in contrast to their counterparts in the instruction group. More importantly, the study found that the learning of rules based on initial memorization of chunks might be regulated by the complexity of linguistic context in which the target rule is deployed. The paper concludes with pedagogical implications for the instruction of grammatical chunks.
\end{abstract}

Keywords: Memorized Chunks; Rule Formation; Chinese Learners of English; Syntacticization

\section{Introduction}

There has been a noticeable increase of interest in formulaic language ${ }^{i}$ within applied linguistics and SLA research. Recognising the important roles of formulaic language in language learning, some researchers propose that the linguistic system is composed of two subsystems: a rule-based system and an exemplar/memory-based system (Skehan, 1998) and that language use is operating on 'open-choice principle' as well as 'idiom principle' (Sinclair, 1991). In both dichotomies, the former consists of generative rules and the latter memorized chunks. While the rule-based system has unlimited creative potential, the exemplar-based system clearly excels in processing speed. In view of the fact that neither the rule system nor the exemplar system is ideal separately, a question naturally arises of 'exploring how the two systems might work harmoniously together' (Skehan, 1998: 89). Debate in both L1 and L2 acquisition research, in effect, has largely centred on whether learners' memorized chunks (initially unanalysed utterances) contribute to their development of an emerging grammatical competence.

SLA research has offered evidence indicating that some aspects of language learning (if not all) can be regarded as a process of breaking down initially unanalysed chunks of language in long-term memory into smaller, more productive units (Bialystok \& Ryan, 1985; N. Ellis, 1996; Myles, Hooper, \& Mitchell, 1998; Myles, Mitchell, \& Hooper, 1999; Peters, 1983). First language acquisition research (see, e.g. Berman, 1986; Lieven, Julian, \& Gillian, 1997; Peters, 1983, 1985; Tomasello, 2000) has produced evidence that memorized unanalysed chunks may serve as a database for the learning of grammar at a later stage.

In the case of second language learning, however, Skehan (1998) doubts the possibility of the process of 'syntacticization' devoid of appropriate instruction. He holds that (adult) second language learner will probably not move on to 'syntacticization' beyond the initial stage of 'lexicalization' (see Skehan, 1998: 89-91 for discussion of 'sequence of exemplars of lexical items') once the critical period is past. In other words, it is argued that L2 learners will not process beyond the accumulation of chunks without 'continual pressure on learners to analyze the linguistic units they are using' (Skehan, 1998: 91).

The study reported here is an attempt to evaluate the issue through a classroom experiment. It investigates the acquisition of grammatical rules beyond initial memorization of unanalysed chunks by low-intermediate classroom EFL learners in China, focusing on the structure of despite $+N P$. The report looks into whether rote-memorization alone is sufficient for the development of rule-based system in the case of adult learners. 
In the following section, I begin by reviewing the relevant theoretical and empirical research that serves as the background of the study. I then report on the method of the study and results. Next follows a discussion of the findings. The paper concludes with a brief summary of the findings and pedagogical implications.

\section{Background}

\subsection{Chunks and adult L2 learning}

Earlier studies (e.g. R. Ellis, 1984; Hakuta, 1974, 1976; Huang \& Hatch, 1978; Wong-Fillmore, 1976; Yumoto, 1992) provided evidence that the use of chunks is a very common phenomenon in the early stages of L2 acquisition, and learners gradually analyse and generalise them into rules.

More recently, Myles, et al. (1998; 1999), in their longitudinal study of 16 child beginner classroom learners of French, found that most of the learners not only gradually 'unpacked' their early chunks, but also used parts of them productively in the generation of new utterances. These findings demonstrated that rote-learning of chunks contributes to the development of a creative language capacity and that the learning of chunks and the construction of rules interact and actively feed into one another.

The above mentioned studies, it should be noted, have almost exclusively employed as subjects learners who are in the very early stages of L2 learning either in classroom or natural learning environment. That is, learners in these studies are mostly child beginners who are cognitively immature and have not developed grammatical awareness. Syntacticization seems to occur only during the critical period because it was programmed to do so following a maturational schedule (Pinker, 1994).

Empirical evidence in SLA in support of this notion, though remaining sparse, is not non-existent. Tode (2003), for instance, investigated the extent to which adult beginning Japanese EFL classroom learners learned the rule of the copular be beyond initial memorization of chunks without explicit instruction. A total of 218 students (aged from 13 to 15) participating in the study were exposed to exemplars of the copula be through their textbook, but did not receive explicit instruction of the formation rule. Two groups of students (111 from Grade 8 and 107 from Grade $9^{\text {iii }}$ ) were included in the sample in an attempt to determine whether or not a 1-year difference in exposure to the exemplars is sufficient to make a difference in the inductive learning of the target rule. Data gathered through a written elicitation test showed that there was no significant difference in the progress of the two groups and that less than half the participants learned the copular rule successfully. These findings indicated that mere exposure to linguistic data may not be sufficient to guarantee an appropriate induction from exemplars for classroom learners and that the explicit teaching of rules might be necessary.

As mentioned earlier, the lack of congruence in the findings of the above studies might be a consequence partly due to maturational effects. That is to say, adult EFL learners may experience more difficulty compared with their child counterparts in terms of implicitly acquiring rules beyond the initial memorization of unanalysed chunks. Adult learners, however, are considered to have better meta-awareness and analytical ability than children; as a result, they can understand a language as a formal set of rules (Wray, 2000). With no pretense of addressing the difficult issue of why adults' capacity to learn abstract patterns implicitly is extremely limited (as suggested by recent studies of artificial grammar learning in experimental psychology such as Perruchet \& Pacteau, 1991; Redington \& Chater, 1996; Shanks \& St. John, 1994) compared to their child counterparts despite their apparent strength in analytical ability, the present study addresses the question of to what extent and under what conditions the adult EFL learners are able to induce rules from exemplars they are exposed to.

\subsection{Implicit or explicit induction?}

Some psycholinguists (see, e.g., DeKeyser, 1995; Williams, 1999) discuss learning rules from two dimensions: implicit versus explicit, and inductive versus deductive.

Inductive learning is defined as 'the process that goes from the specific to the general, namely first the real language use, from which will 'emerge' patterns and generalisations' (Decoo, 1996: 96). The advantage of induction, according to Hammerly (1975), is that the knowledge acquired is couched in terms that make sense to the individual student rather than in terms imposed by the instructor. Analysis of chunks can be considered to be inductive learning (Tode, 2003).

Moving on to the other dichotomy, implicit learning is defined as learning that 'occurs without concurrent awareness of what is being learned, through memorization of instances, inferencing of rules without awareness, or both' while explicit learning is considered as a process that 'occurs with concurrent awareness of what is being learned' (DeKeyser, 1995: 380).

Returning to the issue of the differential capability of inferring rules from a set of exemplars (unanalysed chunks) between adult and child learners, a question of great relevance to the current discussion is: Can the process of induction from chunks be implicit in the case of adult second language learning? This inquiry, in essence, begs a more general question of whether implicit learning is possible in adult SLA. Laboratory psychological experiment with artificial language (cf. Reber, 1967; Williams, 1999) seems to endorse the assumption that (adult) learners tend to adopt an implicit as opposed to explicit mode of learning. There is evidence that subjects under task conditions do seem to be able to form long-term memory representations of input material and these representations do seem to inform subsequent grammaticality judgement on previously unseen items without the subjects' awareness. As of yet, it cannot be presumed that a theory derived from experiments with artificial grammars can be extended to encompass the learning of natural languages (Schmidt, 1994). Indeed, studies that have used real or natural-like language system (see, e.g. 
DeKeyser, 1995, 2000; N. Ellis, 1993; Robinson, 1996, 1997) have not yielded similar results to that obtained from laboratory studies. This appears to lend support to Bley-Vroman's $(1988,1989)$ Fundamental Difference Hypothesis, which states that whereas children are known to learn language almost completely through (implicit) domain-specific mechanisms, adults have largely lost the ability to learn a language without reflecting on its structure and have to use alternative mechanisms, drawing especially on their problem-solving capacities, that is, mechanisms for explicit learning, to learn a second language. Therefore, (explicit) instruction is seen as a defining characteristic of adult SLA (Bley-Vroman, 1989). Although N. Ellis believes that language learning - L2 learning included - is largely implicit (2002) and that L2 grammar is acquired through implicit analysis of lexical sequences that are memorized by chunking process (1996), he also admits that adult learners have sophisticated formal means of thinking and treat language as an object of explicit learning - that is, of conscious problem-solving and deduction - to a much greater degree than can children (N. Ellis, 1994). From a reading of this literature, it might be concluded, therefore, that adult human has a potential for implicit generalisation through inductive learning mechanism theoretically, but this capacity seems to be greatly constrained in practical learning situations, particularly among adult foreign language learners in classroom context. With implicit learning mechanisms unavailable, adult learners may resort to explicit learning mechanism to induce rules.

Although adults are far better at figuring out language structures explicitly than children because of their higher level of general cognitive maturity, some researchers hold a relatively reserved attitude towards the possibility of explicit induction of rules from chunks. For instance, DeKeyser (DeKeyser, 1995, 2000) does not applaud that adult learners necessarily succeed in inducing rules explicitly from chunks. He (1995) identifies through an experiment two conditions under which explicit induction may be working well: (1) easy rules ${ }^{\text {iii }}$, and (2) high aptitude learners. In addition, other researchers emphasize the amount of input necessary for inductive learning (Yamaoka, 2004; cited in Tode, 2003) or the prime role of frequency in the 'abstraction of regularities' (N. Ellis, 2002).

\subsection{Learning 'despite the fact that' as a chunk}

\subsubsection{An empirical study}

I performed a quasi-experimental study of adult Chinese learners learning English (Yu, 2009). In order to investigate whether two different means of learning a word sequence leads to differential outcome of the acquisition of the imbedded grammatical structure, I targeted despite the fact that, a word sequence of grammatical importance. It was selected simply for pedagogical reasons as its internal structure proves problematic for Chinese learners due to L1 influence (in this case, negative transfer). Chinese learners of English tend to treat despite as a conjunction rather than a preposition due to L1 transfer (viz. the Chinese equivalent jinguan functions as a conjunction and thus is followed by a sentence). Therefore, they more often than not produce sentence like "*He attended the class despite he was ill."

The participants of the study were randomly divided into two groups with one group being taught the grammatical structure despite $+N P$ through explicit instruction and the other required to commit to memory the word string despite the fact that through repetition or recitation deprived of explicit teaching (similar to the treatment given to groups in the present study; see 3.4). I explained the usage of the word despite explicitly (i.e. despite $+N P$ ) to instruction group and provided two examples: a) He went to school as usual despite the fact that he was ill. b) Despite the bad weather we enjoyed our holiday. The memorization group was required to learn three paragraphs by heart, one of which was used in the present study (see Appendix D), containing an instance of despite the fact that and one of despite $+N P$ more generally. It turns out, following the result of a written translation test ${ }^{\mathrm{iv}}$, that the recitation group significantly outperformed the instruction group in terms of the use of the target sequence despite the fact that.

\subsubsection{Questions unanswered}

The highly significant out-performance ( $p=0.006<.01 \mathrm{cf}$. Yu, 2009) of the recitation group over the instruction group in the translation test ${ }^{\mathrm{v}}$, however, does not blind me to the fact that most learners (13 out of 17 , i.e. nearly $\left.76 \%\right)$ in the recitation group who scored unanimously used the sequence despite the fact that in both parts of the testing item. What is revealed more than anything else is that despite the fact that might be memorized as an unanalysed whole, or what Taguchi (2008) call 'grammatical chunk'vi. More importantly, I noticed that some learners among those who did not score produced the right structure (by using the target sequence despite the fact that) in the first half but made it wrong in the second probably due to my accidental use of the word shishi (meaning 'fact' in Chinese) when constructing the first half of the rubric following despite (but not in the second; see footnote 5). For instance, one student responded like this: "Despite the fact that I spend so much time to recite, despite the process of reciting is very difficult." This inconsistency in some students' output seems to suggest that it is too early to draw the conclusion that the learners have learned the internal rule beyond initial memorization of chunks.

\subsubsection{A hypothesis}

Learning the chunk despite the fact that under the memory-task condition, or what Robinson (1995) calls the 'implicit condition', might be characterised as an 'incidental condition' in which learning is independent of analytic ability and awareness (Robinson, 1995). The fact that awareness did not lead to superior incidental learning is considered as 'a consequence of the fact that awareness was of semantic and lexical aspects of the sentences' (Robinson, 1995: 342). An immediate corollary of this is that learners are less likely to search for syntactic rules in this condition. True as that may be, it should be noted that participants in the above-mentioned study had been placed in a typical test-oriented school education environment since they formally started their English learning. Consequently, instructional practices in most part of China are still dominated by traditional language teaching methodologies including grammar-translation method 
mainly focusing on explicit illustration of grammar rules (cf. Hu, 2005). It can be speculated that learners, in such a learning context, are very likely to direct their attention to syntactic rules even in the incidental condition (Tode, 2003). Thus viewed, Robinson's argument does not seem to fit very well in the case of Chinese classroom learners in the above mentioned study ${ }^{\text {vii }}$. Moreover, a highly controlled written test employed in the study afforded the learners an advantage in terms of control over use of knowledge ${ }^{\text {viii }}$ compared with an oral test. That is to say, learners who were measured in a written test mode and therefore free from real-time communication pressure, were given enough time to manipulate their responses, perhaps focusing on grammatical analysis ${ }^{\mathrm{ix}}$.

Examined under one of the possible conditions for inducing rules from chunks postulated by DeKeyser (2000), i.e. easy rules, the structure of despite $+N P$ can hardly be considered very difficult, especially when the fact is taken into account that all the learners had at least nine years form-biased classroom instruction and had been admitted to the university ${ }^{\mathrm{x}}$ with scores above the required level. It is important to point out that Chinese students, from the secondary level on, invest a great deal of time and energy in grammar for preparation of written examination (Wen \& Clement, 2003) which is largely 'discrete-point, structurally based' (Burnaby \& Sun, 1989: 228). And dominant (traditional) approach to foreign language teaching is characterised by 'systematic and detailed study of grammar, extensive use of cross-linguistic comparison and translation ...' (Hu, 2002: 93; see also $\mathrm{Hu}, 2005)$.

If this group of learners might arguably be considered equipped with reasonably high analytic ability or the potential of grammatical sensitivity, why is it that they seem to be unable to generalise a rule which is theoretically not difficult for them?

A question that ensues would be: What is (are) the factor(s) inhibiting the learner's analytic ability in this case? I would like to attribute the learners' inability to perform the induction, among other things, to the linguistic circumstances under which the target rule is deployed. In simplified terms, the original sentence containing the target structure is far too complicated or confusing linguistically for the learners to generalise the imbedded rule. Put under scrutiny the original sentence which the recitation group was required to memorise - "Despite the fact that my friends warned me against being taken in, despite everything I've learned, I find that I'm not willing, but positively eager to buy that bridge she mentioned." - I detected at least two elements that might pose hurdles for the learners' analysis: (1) lack of consistency in the way the rule is presented, by which I mean while the first part of the sentence employs despite the fact followed by that-clause, the second part adopts the structure of despite + pron followed by a clause with the relational pronoun being omitted; (2) the complexity ${ }^{\mathrm{xi}}$ of the that-clause immediately succeeding the target syntactic structure despite $+N P$, which apparently imposes a heavy processing load on the learners, who are engaged in decoding the message, therefore, leaving little attention to the preceded target structure.

Following this line of reasoning, I hypothesised that if the linguistic context in which the target rule is imbedded is made simpler and straightforward, the learner would be in a better position to figure out the target rule from memorized chunks.

\section{The present study}

The issues reviewed above underpin the motivation for the present study. The questions I sought to address, therefore, are: (1) Is absolute success of (explicit) induction from memorized exemplars (chunks) possible with experienced adult L2 classroom learners? (2) Are learners who are imposed on instances (exemplars) with a simple linguistic context more able to analyse the rule than learners who are provided with complicated sentences under the memory-task condition?

\subsection{Subjects}

The subjects were freshmen from three schools of a Chinese university, all in the second semester of their first year. They majored in law with different specialities. According to the results of English Matriculation Test, the subjects had been assigned to low-intermediate parallel classes ${ }^{\text {xii }}$. They had learned English from the same standard textbooks approved by the Ministry of Education for six years, taken the same entrance examination, and been recruited into the university with scores above the required level. The subjects naturally formed three groups since they were from three intact classes. The three classes were taught by one English teacher. More background information gathered from a questionnaire is summarised in Table 1.

Table 1. Subjects' background

\begin{tabular}{lccc}
\hline Subjects(N) & average age & years of learning English & speciality \\
Group 1 $(\mathrm{n}=44)$ & 19.41 & 9.25 & Civil \& Commercial Law \\
Group 2(n=44) & 19.35 & 9.21 & Criminal Law \\
Group 2(n=46) & 19.36 & 9.17 & Economic \& Trade Law \\
\hline
\end{tabular}

\subsection{Design and material}

The study employed an experimental design (see Table 2) with three groups of participants being randomly assigned to memorization group one (henceforth the MG1), memorization group two (henceforth the MG2) and the instruction group (henceforth the IG). IG received direct instruction on the target grammatical item despite $+N P$ in normal class time while the MG1 and MG2 were given an after-class assignment of memorizing one paragraph containing the target word sequence despite the fact that (see 3.4 for more information). MG1 was given a simpler exemplar (see Appendix C) to memorise than the one allocated to MG2 (see Appendix D). IG served as a contrast for any effect or change observed in memorization groups. 
Table 2. Design and procedures

\begin{tabular}{|c|c|c|}
\hline \multicolumn{2}{|c|}{ Stage of sessions Date } & MG1 \& MG2 \\
\hline Pre-test & $14 / 03 / 08$ & translation test \\
\hline Treatment & $19 / 03 / 08$ & classroom instruction \\
\hline Recitation test & $21 / 03 / 08$ & writing down the paragraph from memory \\
\hline Post-test & $26 / 03 / 08$ & translation test \\
\hline Post-test & $2 / 04 / 08$ & multiple choice test \\
\hline Interview & $2 / 04 / 08$ & retrospective think-aloud \\
\hline
\end{tabular}

A translation test (see Appendix A) was administered as a pre-test to all subjects, the aims being (1) to distinguish the few students who were able to use the target rule correctly from those who were not and (2) to enable a comparison with the post-test. The post-test consists of a translation test and a multiple choice test. The numbers of surviving subjects were reduced from 44 to 38 in MG1, 44 to 39 in MG2 and from 46 to 40 in IG because (1) the students who had already mastered the target structure were excluded from the experiment according to the result of the pre-test; (2) the students who were absent in one of the four classes during which all tests and treatment were administered were not counted in statistical procedures; and (3) students in MG1 and MG2 who had not learned by heart the assigned paragraph (as is attested to in the recitation test) were not considered as subjects in the study. The recitation test was administered to all three groups to ensure the exclusion of both those in MG1 and MG2 who had not learned by heart the paragraph as required and those in IG who had memorized the one allotted to MG2 voluntarily ${ }^{\text {xiii }}$.

The research tool employed were two types of written tests (translation in both pre-test and post-test and multiple choice in post-test only; see Table 2) devised to show the learners' use and understanding of the target structure despite $+N P$. The specifically designed tests aim to check whether the learners in three groups would respond differentially in two types of tests.

In the present study, rule formation was operationalized as being able to make correct judgements on the use of the rule in the form-oriented condition, as was measured by a multiple-choice test ${ }^{\mathrm{xiv}}$ (see Appendix B). In this test, the subjects were asked to choose the right answer(s) from four choices that were four versions of English translation of a Chinese sentence. The four translation versions differ only in the realisation of the structure of despite $+N P$. Of the four choices, two of them are legitimate translations (one employing the word sequence despite the fact that and the other the general structure despite $+N P$; see Appendix B 'Multiple choice test') and the other two defective serving as distractors. The purpose of multiple-choice task was to re-examine whether or not the subjects have correctly analysed the memorized word sequence, for the learners' attention is supposed to be more on the form than on the message in this test design visà-vis the translation test. The reason why I included two correct answers was mainly to test whether the participants in two MGs had generated the rule despite $+N P$ from the memorized exemplar despite the fact that. The translation tests in the study were used for gauging the participants' ability to use the target chunk in a meaning-based condition. In the translation tests, the subjects were required to translate a sentence from Chinese to English with mandatory use of the word despite (see Appendix A\&B), which helped elicit the data expected.

Brief interviews with some students from each group (2 from IG and 3 from MG1 and MG2 respectively) were conducted immediately after the multiple-choice test for eliciting learners' own explanations of their choices. The students' retrospective think-aloud reports were recorded and later transcribed.

\subsection{Procedure}

Data were collected during regular class time in the subjects' classrooms at the beginning of the second semester in the academic year 2007-2008. To avoid test effect, target testing items were mixed with seven others testing the students' mastery of recently taught phrases or structures, and two tests in post-test were administered one week apart. Three groups had completed the tests on the same day during regular class time. In order to avoid invalid data, the subjects were reminded that the words and expressions given in the brackets (e.g. 'despite' in the item of concern) must be used in the translation test and that there may or may not be only one right answer in the multiple-choice test. The participants were also informed that the results of the tests were not relevant to their grades but for research purpose only.

\subsection{Instruction and assignment}

The classroom instruction for IG was carried out in one of the normal classes that involved dealing with the text section containing the target structure. The instruction lasting around 10 minutes consisted of two parts: explicit presentation and giving examples. The English teacher explained in both English and Chinese that the word 'despite', differently from 'although', is a preposition which needs to be postmodified by a noun phrase rather than a sentence. In order to make the notion more salient, the teacher wrote clearly on the blackboard the structure despite $+N P$. Immediately following the explanation, the teacher provided two examples in both oral and written form: a) He went to school as usual despite the fact that he was ill. b) Despite the bad weather we enjoyed our holiday. In addition, the teacher reinforced the concept by drawing the students' attention to a long sentence in the textbook in which the target structure is employed - "Despite the fact that my friends warned me against being taken in, despite everything I've learned, I find 
The explanation of target rules, however, was deliberately eschewed in the normal classes given to MG1 and MG2. Instead, subjects in these groups were required to learn one paragraph by heart. MG1 was assigned a paragraph (see Appendix C) slightly adapted from the biography authored by Lucia Raatma (2006). This is follow-up task after an inclass fast reading exercise ${ }^{\mathrm{xv}}$ using the episode about Oprah's (a well-known American talk-show hostess) turning point in career. MG2 was required to memorise the paragraph (see Appendix D) in the textbook containing the sentence mentioned at the end of the last paragraph. The target rule under investigation was utilised in two of the sentences of the two paragraphs assigned to two groups respectively. The subjects spent on average about 15 minutes ${ }^{\text {xvi }}$ finishing memorizing the paragraph given.

\subsection{Scoring and analysis}

I scored all the pre- and post- tests. In all tests, one item was scored 1 (correct) and 0 (incorrect). In the post-test, 0.5 is given if the subject gets half of testing point right, this is because, in the translation test, some learners only enacted the right use in one of the two places where the target rule is required to be applied; and in the multiple choice test, some subjects chose only one of the two appropriate versions of translation or chose two versions with one being illegitimate. The same scoring standard was used in both tests to make sure that data elicited would be comparable across tests.

What needs to be pointed out is that there are two similar testing items in the multiple-choice test (see Appendix B) with exactly the same testing purpose (i.e. to check whether the participants are able to make appropriate judgement on the usage of target rule despite $+N P$ ). The repetitive design here is intended for a detector of the participants who ticked the answer(s) at will or randomly without any consideration. It is assumed that a serious participant should respond consistently on both items, namely, if one chooses A (and C) in the first testing item, s/he will be expected to tick D (and B) accordingly ${ }^{\text {xvii }}$. If one fails to do so, his/her response will be considered to be invalid and therefore excluded from statistics. As a result, the final numbers of the participants were changed to 35 (from 38) in MG1, 33 (from 39) in MG2 and 36 (from 40) in IG. Since the double-item design in the multiple-choice test was simply for enhancing the reliability of the data, only one item was included in statistical processing.

The solitary standard for scoring the translation test was the target grammatical focus, i.e. whether or not the subject produced a noun phrase or a sentence following the given word 'despite'. Excluded from consideration were such factors as vocabulary, spelling or other grammar points. The scoring was thus highly objective and unambiguous. All the data collected were put into SPSS 17.0 to compute the descriptive statistics and run the analysis of variance (ANOVA). The recall data from interviews were analysed qualitatively focusing on content and the results are to be presented in the discussion section.

\section{Results}

Table 3 displays the means and standard deviation of the participants' performance on the translation test and the multiple-choice test.

Table 3 shows that there is a different degree and direction of variance both within and across groups. In the translation test, the disparity of mean scores among the three groups is apparent (MG1, $M=.6857 ; \mathrm{MG} 2, M=.5606 ; \mathrm{IG}, M=.3889$ ), especially between memorization group and instruction group if viewed in a broader category. From translation test (Abbr. TraT) to multiple-choice test (Abbr. MulT), MG1 showed a slight decrease (TraT, $M=.6857 ;$ MulT, $M=.6571$ ) and MG2 a higher degree of drop (TraT, $M=.5606$; MulT, $M=.4848)$ while IG exhibited a remarkable growth ${ }^{\text {xiii }}($ TraT, $M=.3889 ;$ MulT, $M=.6944)$.

Table 3. Means and standard deviations for MG1, MG2 and IG

\begin{tabular}{lllll}
\hline & & MG1 $(\mathrm{n}=35)$ & MG2(n=33) & IG(n=36) \\
\hline Translation test & Mean & .6857 & .5606 & .3889 \\
& SD & .40376 & .44647 & .46462 \\
\hline Multiple choice test & Mean & .6571 & .4848 & .6944 \\
& SD & .39800 & .40475 & .41880 \\
\hline
\end{tabular}

Table 4. Differences among MG1, MG2 and IG on the translation test and multiple choice test

\begin{tabular}{llllll}
\hline & Groups & Sig. & df & F & Sig. \\
\hline Translation test & MG1 versus MG2 & .243 & 2 & 4.092 & .020 \\
& MG1 versus IG & .005 & & & \\
& MG2 versus IG & .108 & & & \\
\hline Multiple choice test & MG1 versus MG2 & .084 & 2 & 2.555 & .083 \\
& MG1 versus IG & .701 & & & \\
& MG2 versus IG & .035 & & & \\
\hline
\end{tabular}


An One-way ANOVA was used to evaluate the overall differences between groups and Post Hoc $t$-Tests to make multiple comparisons in group pairs.

As shown in Table 4 , there was a significant difference $(p=.020<.05)$ among three groups on the translation test. In comparison, overall difference between groups on the multiple-choice test was not statistically significant $(p=.083>.05)$, suggesting a shrinking disparity of performance on this type of test. The overall degree of variance between groups on one type of test does not equally apply to multiple comparisons in pairing groups. Closer inspection of the third column of Table 4 reveals that there is a mixed degree of differences in pairwise comparison. On the translation test, the differences between MG1 and MG2 ( $p=.243>.05)$, MG1 and IG $(p=.108>.05)$ are not significant despite the overall significant disparity between groups. Similarly, on the multiple-choice test, there is a significant difference between MG2 and IG $(p=.035<.05)$ albeit the overall statistically insignificant difference between groups. Figure 1 provides a better visual display of the between-group differences.

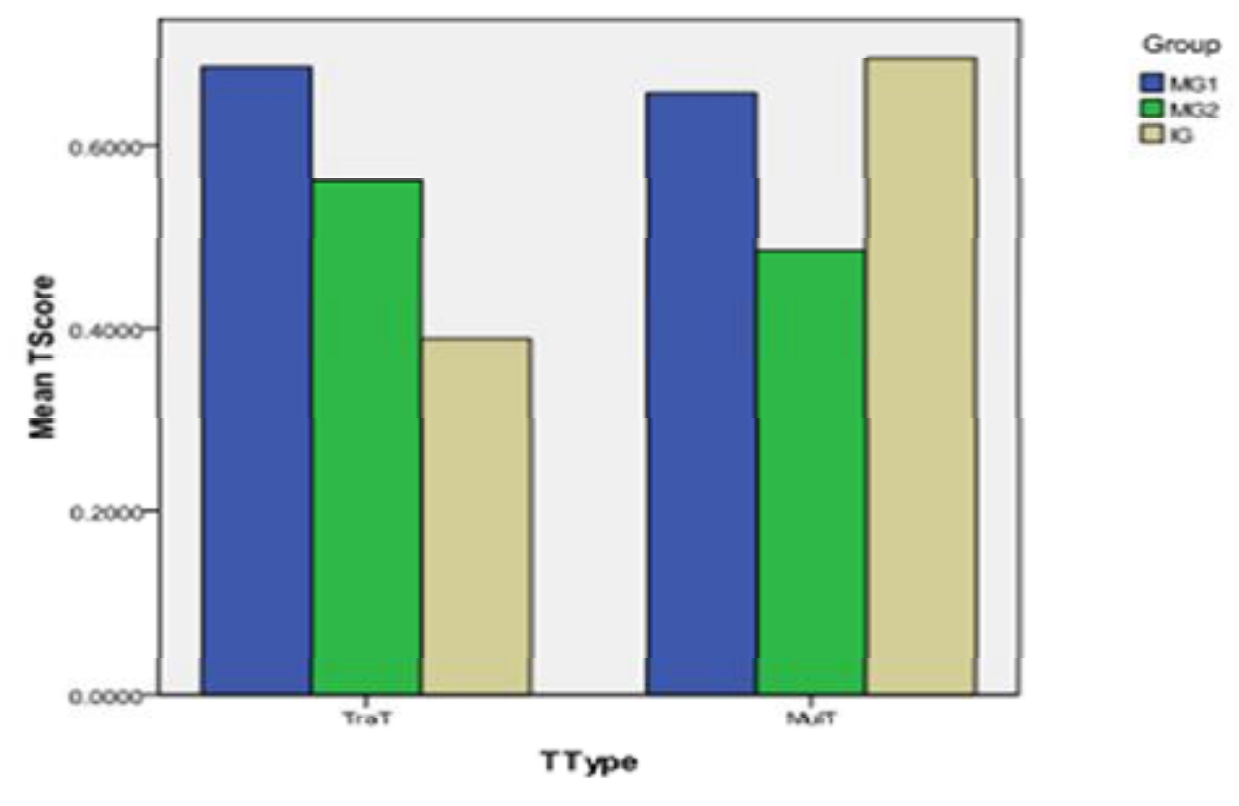

Between-group differences in two types of tests

Figure 1. Between-group differences

Note. TType=test type; Mean Tscore=mean scores on tests; TraT=translation test; MulT=multiple -choice test

\section{Discussion}

The present study differs from previous studies in two respects: First, while previous research investigated the possibility of rule formation from unanalysed chunks with learners who had no or little experience of explicit grammar instruction, this study examine the same issue with learners who had on average nine years classroom grammar instruction, and hence developing a considerably higher degree of grammar awareness than learners in previous studies. Second, while the learners in the previous studies had been exposed to a number of exemplars for an extended period of at least one semester (e.g., Myles, et al., 1998; Taguchi, 2007; Tode, 2003), the learners in the present study were asked to commit only two exemplars to memory in an intensive mode.

Despite the short duration of the study, the data collected over a period of two weeks generated results triggering a number of questions that warrant explication. The next section presents and discusses these questions based on both quantitative and qualitative data.

\subsection{Quantitative analysis}

First and foremost is the question of whether or not the appropriate use of a word sequence means successful induction of the imbedded rule beyond initial memorization. In Widdowson's (1989: 131) words, '[C]an we have ... an ability to use language appropriately, without grammatical knowledge or the ability to compose or decompose sentences with reference to it?' Back to the test results, does the performance of memorization groups in the translation test remain more or less the same in the multiple-choice test? To estimate the degree of variance across tests of individual group, I employed a paired-sample $t$-test, the result of which is displayed in Table 5. The fact that the learners in the MG1 performed as well in multiple-choice test as in translation test $(p=.160>.05$; see Table 5), and that MG1 displayed even no significant difference from IG in multiple-choice test $(p=.701>.05$; see Table 4$)$ seems to suggest that learners in this group have learned the rule from the memorized exemplars. The performance of MG2 on the multiple-choice test, however, deteriorate significantly compared with that of translation test (TraT, $M=.5606$; MulT, $M=.4848 ; p=.023$ $<.05$; see Table 5). Why do the two memorization groups display a differential degree of variance from translation test to multiple-choice test? To answer this question, I re-examined the data from an alternative perspective, namely, the 
scoring distribution of the two tests across the three groups. Table 6 gives a detailed tally in this regard. As indicated in Table 6 , the change of percentage of those who scored 1 and 0.5 may contribute to the variance across two types of tests since the number of participants who scored 0 remains unchanged in both groups. The percentage of participants in MG2 who scored $1(\mathrm{n}=15)$ dropped drastically from translation test $(45 \%)$ to multiple choice test $(30 \% ; n=10)$ (and accordingly, the percentage of those who scored 0.5 increased radically from $21 \%$ to $36 \%$ ). Change on the same direction also occurs in MG1, but, relative to MG2, the extent of variance is much smaller, i.e. from $57 \%(\mathrm{n}=20)$ to $51 \%$ ( $\mathrm{n}=18$ ) for 1 point gainer (and $23 \%$ to $29 \%$ for 0.5 gainer). Translated into simple terms, $90 \%$ (18 out of 20 ) of those in MG1 who scored 1 point on translation test also fully scored on multiple-choice test while the percentage in MG2 comes only $67 \%$. In other words, a higher percentage of participants in MG1 seemed to have successfully induced rules from memorized exemplars. The result thus confirms my hypothesis that rules realised in simpler linguistic context might be easier for induction. Returning to the question set out at the beginning of the paragraph, namely, whether the appropriate use of a 'grammatical chunk' (as was discussed in 2.3.2) equates the successful induction of the rule contained the chunk, the answer would seem to be 'no'. Indeed, L2 learners may 'learn' without metalinguistic understanding of the grammatical points in question (VandeBerg, 1999) even in the case of experienced learners who tend to impose a grammatical analysis on input. Thus, the result of the study appears to be consistent to DeKeyser's (DeKeyser, 2000) assertion that adult learners may not necessarily succeed in explicit induction of rules from chunks because their explicit induction mechanism does not work well except in the case of easy rules and high aptitude learners (DeKeyser, 1995).

Interestingly, the overwhelming majority of those who scored 0.5 in the multiple-choice test in both groups chose the version beginning with despite the fact that with only 2 exceptions ( 1 in each group). What has been suggested here more than anything else is that the learners seemed to have treated despite the fact that as a whole as a result of previous memorization task, which provides additional evidence for the study (Yu, 2009) based on which the current study followed up.

Table 5. Paired-samples $t$-test of translation test and multiple-choice test by MG1, MG2 and IG

\begin{tabular}{llll}
\hline & Translation test & Multiple choice test & Sig. (2-tailed) \\
\hline MG1 & .6857 & .6571 & .160 \\
MG2 & .5606 & .4848 & .023 \\
IG & .3889 & .6944 & .000 \\
\hline
\end{tabular}

Table 6. Scoring distribution of MG1, MG2 and IG on translation test and multiple-choice test

\begin{tabular}{llllllll}
\hline & Scores & \multicolumn{2}{c}{ MG1(N=35) } & \multicolumn{2}{c}{ MG2(N=33) } & \multicolumn{2}{c}{ IG(N=36) } \\
\cline { 2 - 7 } & & $\mathrm{n}$ & $\%$ & $\mathrm{n}$ & $\%$ & $\mathrm{n}$ & $\%$ \\
\hline Translation & 1 & 20 & 57 & 15 & 45 & 12 & 33 \\
test & 0.5 & 8 & 23 & 7 & 21 & 4 & 11 \\
& 0 & 7 & 20 & 11 & 33 & 20 & 56 \\
\hline Multiple & 1 & 18 & 51 & 10 & 30 & 22 & 61 \\
choice test & 0.5 & 10 & 29 & 12 & 36 & 6 & 17 \\
& 0 & 7 & 20 & 11 & 33 & 8 & 22 \\
\hline
\end{tabular}

Note. $\mathrm{N}=$ the total number of individual group; $\mathrm{n}=$ the number of people who get corresponding scores in the second column

Another interesting phenomenon I noticed in passing is that a considerable number of those who scored 0.5 or 0 in MG1 and MG2 chose the item starting with it is a fact that. Instead of deeming it a neglectable coincidence, I prefer to view it as a side effect of the memorization of the sequence despite the fact that. Rather than dismantling the chunk correctly, this strand of participants seemed to have misinterpreted the information conveyed by the memorized exemplar, viz. they appeared to have developed a conception unconsciously that 'despite' has to be connected with 'fact' in one way or another. While it may serve as a supporting argument for the view of despite the fact that being treated as a chunk by the learners (though there is a distortion of memory), the alarming number of participants choosing it is a fact that also indicates their inability to induce the target rule from the exemplar.

Here comes the second question: Is the form-focused judgement in the multiple-choice test a reliable source of evidence concerning the current issue in question? To put it alternatively, does correct choice in the multiple-choice test safely mean the genuine command of the target rule? To investigate this, I interviewed some participants who made the complete and correct choice in order to seek an emic-perspective explanation for their perfect judgement. My analysis of data in this facet is presented in the next section.

\subsection{Qualitative analysis}

The recall data from interviews revealed rather different approaches to making choices in the multiple-choice test across three groups. For the students from IG, as expected, their answers were quite straightforward. One of them stated: 
The teacher explained the usage of this word [despite] in the class. I cannot remember its exact part of speech. What I only know is that 'despite' is different from 'jinguan' [despite] in Chinese ... it must be followed by a noun rather than a sentence. (Wang)

As for students from the MG2, however, their explanation seemed to be obscure or dubious. The following comment was typical:

The second part of multiple-choice [test] is quite easy for me because I seem to have recited something very similar, especially answer D [everything I've learned]. As for answer B [the fact that I've learned everything], I saw the usage of 'despite the fact that' somewhere. But for the first part, answer A [my friend's warning against being taken in] did make me hesitate for a while. I don't know why. ...I probably chose it at a guess or by intuition. (Chen)

Students from MG1 explained their reasoning more or less like this:

We were asked to learn by heart a paragraph about Oprah previously. I cannot remember the exact sentences now, but I'm certain there is an expression like 'despite the fact that'. So I chose $\mathrm{C}$ [the fact that my friend warned me against being taken in]. And I can also recall that there is a sentence starting with 'despite her worries'. I guess 'despite' can be followed by a noun phrase or something like that. So I chose A [my friend's warning against being taken in] as well. (Li)

One salient point emerging from the retrospective protocol appears to be that students from the memorization groups tend to refer to the memorized exemplars for the source of their rule creation. There seemed a conscious effort to learn generalisation by retrieving instances of previous input on the part of learners in memorization groups. As of yet, the students in MG2 failed to induce the rule beyond wild guess while those in MG1 seemed to be able to go further to the point very close to the target rule. One may even argue that those in MG1 have succeeded in producing the rule for, they have explicitly stated the rule of despite $+N P$ (see participant Li's account above in bold). I would not go that far to indorse this notion because learners in MG1 seemed to view despite $+N P$ and despite the fact that as two separate usage of the word 'despite', namely, they failed to realise that despite the fact that is simply a realisation of the general rule despite $+N P$. Thus viewed, the rule improvised under pressing need for analysis based on memorized exemplars may not be considered as complete as that learned through explicit explanation.

Another point worth noting is that students in MG2 seemed unable to reach what has been achieved by students in MG1. That is to say, they had difficulty generalising the rule based on exemplars committed to memory. My attention was naturally directed to the difference of the exemplars memorized by MG1 and MG2. Why is it that the rule could be forged by students in MG1 (albeit imperfect) from 'despite her worries' but not by those from MG2 based on 'despite everything I've learned'? Interestingly enough, when asked what usage can be induced from the exemplar, students in MG2 provided three types of answers: (1) 'despite' is followed by a pronoun; (2) 'despite' is postmodified by a clause; and (2) 'despite' is followed by a pronoun or noun phrase. It is apparent that students in MG2 are confronted with more than one possibility while inducing the rule from the given exemplar, which is obviously constrained by such factors as grammatical knowledge and language proficiency. The difficulty of rule formation posed on MG2 may well be attributed to the uncertainty or confusion rendered by the tangled linguistic elements displayed in the very exemplar given the learners' limited processing capacity. Thus, there does seem to be some modest support for the hypothesis discussed earlier in the paper that the linguistic context in which the target rule is incarnated may play a role in deriving rules from memorized chunks. Additional evidence in favour of the notion can be found in the result produced by quantitative data presented earlier. As shown in Table 3, the mean scores of MG1 and MG2 in multiple-choice test were .6571 and .4848 respectively, and no significant difference was not found between two groups $(p=.084>.05$; see table 4). However, the lack of statistically significant difference does not mean an absence of visible difference or marginal significant difference. In fact, the two groups did show difference of small magnitude on the scores in multiple-choice test (see Figure 1). Given that the performance of MG1 and MG2 in translation test was substantially insignificant $(p=.243>.05)$, the amplification of gap between the two groups on the performance of the multiple-choice test was obvious. There are two explanations for the disparity. First, since participants in both MGs were devoid of explicit instruction on structure, the burden of discovering the rule is completely on the learner (Skehan, 1998). The fact that MG1 outperformed MG2 may be due to a higher percentage of participants in MG1 with high analytic ability than in MG2. Second, the different exemplars that the participants in two MGs were asked to commit to memory may exert an effect on their induction of the target rule. That is to say, other conditions being equal, a simpler exemplax ${ }^{\text {xix }}$ (as the one assigned to MG1), either in the sense of the length of the sentence or grammatical elements involved, is likely to help the learners ease the burden of extracting the target rule. Given the very similar background of the participants in the two groups (see 3.1), I consider the second possibility a more powerful explanation. Thus, there does seem to be some support for the hypothesis I set out (see 2.3.3) before this experiment study.

In sum, the answers to the research questions - based on quantitative and qualitative data - seem to be that (1) adult L2 learners can experience difficulties in inducing rules merely from memorized exemplars/chunks and (2) learners who have memorized exemplars with a simple linguistic context are more capable of successful induction than those who have committed to memory complicated instances under the memory-based condition.

\section{Conclusion}

The study shows that Chinese adult classroom learners have difficulties in making successful induction from memorized exemplars, which confirms the finding produced by previous research (cf. Tode, 2003). The study also 
suggests that the analysis of memorized chunks into rules may depend on the interplay of a number of factors: processing capacity, the grammar sensitivity or analytic ability on the part of the learner, and, last but not least, the easiness of the rule to be analysed. More importantly, it was found that the easiness cannot simply be defined as the complexity of the rule on its own, rather, it is more or less constrained by the linguistic context in which the rule is realised. The implication of the study for language teaching could, therefore, be that providing the students with exemplars placed in simple linguistic contexts under memorization-task condition may promote form-based processing - in this case - generating rules from chunks.

Albeit tentative, due to the limited measures invoked, the present study produced findings that appear to lend some support to the claim of Widdowson (1989) on the relationship between use and usage. Widdowson (1989: 131) notes that '...the learners might acquire a repertoire of phrases with contextual associations, chunks, so to speak, which have not been analysed into grammatical knowledge.' (see also VandeBerg, 1999 for a similar argument). Since grammatical rule is not necessarily inferred from use of chunks, guidance for structural analyses of individual chunks needs to be introduced. As Skehan (1998: 91) put it, 'if meaning primacy and communicational pressure make for exemplar-based learning, it is important that there should be continual pressure on learners to analyse the linguistic units they are using.' It would be most desirable that the provision of explicit instruction be introduced at a point where efforts of induction have already been made on the part of learners in response to pressure enacted on them to analyse the chunks they are using through pedagogical intervention. In this way, explicit instruction maybe more meaningful to the learner in the sense that initial effort of analysis which comes from within might well facilitate their understanding of the rule taught.

Given the advantage of the combination of both rules and instances (examples) (cf. N. Ellis, 1993) (xx $^{\mathrm{x}}$ explicit instruction of the internal structure of the memorized chunks - which proves difficult for learners to generalise - followed by extensive practice of these chunks would seem to be a no-lose proposition in EFL learning environment. I would suggest that moderate explanation focusing on form serve as a postscript of the memorization task of language use whenever necessary, and a prelude to 'meaning-oriented activities and tasks, which give immediate opportunities for practice and use' (Mitchell, 2000: 297) of target rules.

\section{Acknowledgments}

I would like to thank the students who participated in this research. I, too, want to thank my alma mater, University of Southampton, for generous provision of resources and facilities without which it would be impossible for me to complete the paper.

\section{References}

Berman, R. A. (1986). A step-by-step model of language acquisition. In I. Levin (Ed.), Stage and Structure: Reopening the Debate (pp. 191-219). Norwood, NJ Ablex.

Bialystok, E., \& Ryan, E. (1985). A metacognitive framework for the development of second language skills. In D. L. Forrest-Pressley, G. MacKinnon \& T. Waller (Eds.), Metacognition, cognition, and human performance (pp. 207-252). New York: Academic Press.

Bley-Vroman, R. (1988). The Fundamental character of foreign language learning. In W. Rutherford \& M. Sharwood Smith (Eds.), Grammar and Second Language Teaching: A Book of Reading (pp. 19-30). Boston: Heinle \& Heinle.

Bley-Vroman, R. (1989). What is the logical problem of foreign language learning? In S. Gass \& J. Schachter (Eds.), Linguistic Perspectives on Second Language Acquisition (pp. 41-68). Cambridge, UK: Cambridge University Press.

Burnaby, B., \& Sun, Y.-L. (1989). Chinese teachers' views of western language teaching: Context informs paradigms. TESOL Quarterly, 23(2), 219-238.

Decoo, W. (1996). The induction-deduction opposition: Ambiguities and complexities of the didactic reality. IRAL, 34, 95-118.

DeKeyser, R. M. (1995). Learning second language grammar rules: An experiment with a miniature linguistic system. Studies in Second Language Acquisition, 17, 379-410.

DeKeyser, R. M. (2000). The robustness of critical period effects in second language acquisition. Studies in Second Language Acquisition, 22, 499-533.

Ding, Y.-R. (1987). Foreign language teaching in China: Problems and perspectives. Canadian and International Education, 16(1), 48-61.

Ellis, N. (1993). Rules and instances in foreign language learning: Interactions of explicit and implicit knowledge. European Journal of Cognitive Psychology, 5, 289-318.

Ellis, N. (1996). Sequencing in SLA: Phonological memory, chunking, and points of order. Studies in Second Language Acquisition, 18, 91-126.

Ellis, N. (2002). Frequency effects in language processing: A review with implications for theories of implicit and explicit language acquisition. Studies in Second Language Acquisition, 24, 143-188.

Ellis, N. (2003). Constructions, Chunking, and Connectionism: The emergence of second language structure. In C. 
Doughty \& M. Long (Eds.), Handbook in SLA (pp. 143-188). Oxford: Blackwell.

Ellis, N. (Ed.). (1994). Implicit and explicit learning of languages. San Diego, CA: Academic Press.

Ellis, R. (1984). Formulaic speech in early classroom second language development. TESOL '83.

Ellis, R. (1994). The Study of Second Language Acquisition. Oxford: Oxford University Press.

Hakuta, K. (1974). Prefabricated patterns and the emergence of structure in second language acquisition. Langange Learning, 24, 287-297.

Hakuta, K. (1976). A case study of a Japanese child learning English as a second language. Langauge Learning, 26, 321-351.

Hammerly, H. (1975). The deduction/induction controversy. Modern Language Journal, 75, 15-18.

Hu, G.-W. (2002). Potential cultural resistance to pedagogical imports: The case of communicative language teaching in China. Language, Culture and Curriculum, 15(2), 93-105.

Hu, G.-W. (2005). Contextual influences on instructional practices: A Chinese case for an ecological approach to ELT. TESOL Quarterly, 39(4), 635-660.

Huang, J., \& Hatch, E. M. (1978). A Chinese child's acquisition of English. In E. Hatch. (Ed.), Second Language Acquisition: A Book of Reading. Rowley, Mass: Newbury House.

Johnson, K. (1996). Language Teaching and Skill Learning. Oxford: Blackwell.

Lewis, M. (1993). The Lexical Approach: The State of ELT and a Way Forward. Hove, UK: Language Teaching Publication.

Li, Y.-H., Zhang, P.-R., \& Wang, H.-X. (Eds.). (2001). College English-Integrated Course, Book 1-4. Shanghai: Shanghai Foreign Language Education Press.

Lieven, E. V. M., Julian, M. P., \& Gillian, B. (1997). Lexically-based learning and early grammatical development. Journal of Child Language, 24, 187-219.

Lightbown, P. M. (2008). Transfer appropriate processing as a model for class second language acquisition. In Z.-H. Han (Ed.), Understanding second language process. Clevedon, UK: Multilingual Matters.

Mitchell, R. (2000). Applied linguistics and evidence-based classroom practice: The case of foreign language grammar pedagogy. Applied Linguistics, 21(3), 281-303.

Myles, F., Hooper, J., \& Mitchell, R. (1998). Rote or rule? Exploring the role of formulaic language in classroom foreign language learning. Language leaning, 48, 323-363.

Myles, F., Mitchell, R., \& Hooper, J. (1999). Interrogative chunks in French L2: a basis for creative construction? Studies in Second language Acquisition, 21, 49-80.

Nattinger, J. R., \& DeCarrico, J. S. (1992). Lexical Phrases and Language Teaching. Oxford: Oxford University Press.

Pawley, A., \& Syder, F. H. (1983). Two puzzles for linguistic theory: nativelike selection and nativelike fluency. In J. C. Richards \& R. Schmidt (Eds.), Language and Communication. London: Longman.

Perruchet, P., \& Pacteau, C. (1991). Implicit acquisition of abstract knowledge about artificial grammar: Some methodological and conceptional issues. Journal of Experimental Psychology: General, 120, 112-116.

Peters, A. (1983). The units of language acquisition. Cambridge: Cambridge University Press.

Peters, A. (1985). Language segmentation: Operating principles for the perception and analysis of language. In D. I. SlobinD (Ed.), The cross-linguistic study of language acquisition (Vol. 2, pp. 1029-1067). Hillsdale, NJ: Lawrence Erlbaum.

Pinker, S. (1994). The Language Instinct. Allen Lane: The Penguin Press.

Raatma, L. (2006). Oprah Winfrey. Beijing: China Shuji Publishing House.

Reber, A. S. (1967). Implicit learning of artificial grammars. Journal of Verbal Learning and Verbal Behaviour, 77, 317327.

Redington, M., \& Chater, N. (1996). Transfer in artificial grammar learning. Journal of Experimental Psychology: General, 125, 123-138.

Robinson, P. (1995). Aptitude, awareness, and the fundamental similarity of implicit and explicit second language learning. In R. Schmidt (Ed.), Attention and Awareness in Foreign Language Learning. Honolulu, HI: University of Hawaii.

Robinson, P. (1996). Learning simple and complex second language rules under implicit, incidental, rule-search, and instructed conditions. Studies in Second Language Acquisition, 18(1), 27-68.

Robinson, P. (1997). Generalizability and automaticity of second language learning under implicit, incidental, enhanced, and instructed conditions. Studies in Second Language Acquisition, 19, 223-247.

Schmidt, R. (1994). Implicit learning and the cognitive unconscious: Of artificial grammmars and SLA. In N. Ellis (Ed.), Implicit and Explicit Learning of Languages. London: Academic Press. 
Schmitt, N. (2000a). Lexical chunks. ELT Journal, 54(4), 400-401.

Schmitt, N. (2000b). Vocabulary in language teaching. New York: Cambridge University Press.

Scott, V. (1989). An empirical study of explicit and implicit teaching strategies in foreign language education. Modern Language Journal, 71, 14-22.

Shanks, D. R., \& St. John, M. F. (1994). Characteristics of dissociable human learning systems. Behavioural and Brain Sciences, 17, 367-395.

Sinclair, J. M. (1991). Corpus, Concordance, Collocation. Oxford: Oxford University Press.

Skehan, P. (1998). A Cognitive approach to Language Learning. Oxford: Oxford University Press.

Taguchi, N. (2007). Chunk learning and the development of spoken discourse in a Japanese as a foreign language classroom. Language Teaching Research, 11(4), 433-457.

Taguchi, N. (2008). Building Language Blocks in L2 Japanese: Chunk Learning and the Development of Complexity and Fluency in Spoken Production. Foreign Language Annals, 41(1), 132 - 156.

Tode, T. (2003). From unanalyzed chunks to rules: The learning of the English copula be by beginning Japanese learners of English. IRAL, 41, 23-53.

Tomasello, M. (2000). The item-based nature of children's early syntactic development. Trends in Cognitive Sciences, 4, 156-163.

VandeBerg, C. K. (1999). Metalinguistic coompetence of beginning French students. French Review, 72, 644-657.

Wen, W. P., \& Clement, R. (2003). A Chinese conceptualisation of willingness to communicate in ESL. Language, Culture and Curriculum, 16(1), 18-38.

White, L. (1991). Adverb placement in second language acquisition: Some effects of positive and negative evidence in the classroom. Second Language Research, 7, 133-161.

Widdowson, H. (1989). Knowledge of language and ability for use. Applied Linguistics, 10, 128-137.

Williams, J. N. (1999). Memory, Attention, and Inductive Learning. Studies in Second Language Acquisition 21(1), 1-48.

Wong-Fillmore, L. (1976). The second time around: Cognitive and social strategies in second language acquisition. Unpublished $\mathrm{PhD}$ thesis, Stanford University.

Wray, A. (2000). Formulaic sequences in second language teaching: Principles and practice. Applied Linguistics, 21, 463-489.

Wray, A. (2002). Formulaic Language and the Lexicon. Cambridge: Cambridge University Press.

Yu, X. (2009). A formal criterion for identifying lexical phrases: Implication from a classroom experiment. System, 37(4), 689-699.

Yumoto, K. (1992). From formulaic speech to creative speech (Research/technical report (ERIC Document Reproduction Service) No. ED 404869).

\section{Appendix A:}

\section{Pre-test}

Please translate the following sentences using words and expressions given in the brackets.

Jinguan(despite) ta shiye hen chenggong, ta de geren shenhuo

despite she career very successful she Mod personal life

renran jian'nan.

still difficult

\section{Appendix B:}

\section{Post-test}

\section{Translation test}

Please translate the following sentences using words and expressions given in the brackets. jinguan(despite) ta zai banshang zui chongming shi shishi, jinguan(despite)

despite she in class best smart is fact despite

ta xueye chenggong, meiyou ren yinwei chongming biaoyong ta.

she academic work successful no people because smart praise her 


\section{Multiple-choice test}

Please choose the right version(s) of translation for the following sentence :

Jinguan pengyou tixing wo buyao shangdang, jinguan wo ye zhang le

despite friend warn me not take in despite $I$ also learn $p f v$

bushao jianshi, wo faxian ziji haishi bujin yuanyi, erqie zhengde

much knowledge I find myself also notonly willing butalso truly

kewang maixia ta shuo de neizuo qiao.

eager buy she mention Mod that bridge

Despite
A. my friend's warning against being taken in
B. my friend warned me against being taken in
C. the fact that my friend warned me against being taken in
D. it is a fact that my friend warned me against being taken in

Despite
A. it is a fact that I've learned everything
B. the fact that I've learned everything
C. I've learned everything
D. everything I've learned

I find that I'm not only willing, but positively eager to buy that bridge she mentioned.

\section{Appendix C:}

When Oprah first thought about moving to Chicago, she was worried. Despite her worries, Oprah loved Chicago. She remembers, "I set foot in this city and just walking down the street, it was like roots, like the motherland. I knew I belonged here." The Chicago audience immediately loved Oprah too. A.M. Chicago was a big hit, and it beat Donahue in the ratings. At the same time, she was often scared that the show would fail despite the fact that Oprah was good at her job. (85 words; emphasis added)

\section{Appendix D:}

Yet superwomen tales continue to charm me. Despite the fact that my friend warned me against being taken in, despite everything I've learned, I find that I'm not willing, but positively eager to buy that bridge she mentioned. Why? I suppose it has something to do with the appeal of an optimistic approach to life -- and the fact that extraordinary deeds have been accomplished by determined individuals who refused to believe that "you can't" was the final word on their dreams. (82 words; emphasis added)

\section{Notes}

${ }^{i}$ Formulaic language has also been discussed under terms of formulas (R. Ellis, 1994), formulaic speech (WongFillmore, 1976), lexicalised sentence stems (Pawley \& Syder, 1983), holophrastic expression (Peters, 1983) and lexical patterns and collocational knowledge (Lewis, 1993; Schmitt, 2000b). The most commonly used labels are lexical chunks and lexical phrases (Schmitt, 2000a), but Wray (2002: 9) suggests using formulaic sequences .

${ }^{\text {ii }}$ English teaching in Japan begins as an academic subject in the seventh grade (the $1^{\text {st }}$ year of junior high school).

iii The result of a controlled experiment (Robinson, 1996) showed that simple rules were indeed learnt more easily than complex rules under all (i.e. implicit, incidental, rule-search and instructed) conditions.

${ }^{\text {iv }}$ It was assumed that a timed translation test has more potential to show the subjects' performance on the procedural level (i.e. using knowledge under real operating conditions) than on the declarative level (i.e. explicitly stating the grammatical knowledge).

${ }^{\mathrm{V}}$ The original testing item is as follows:

Despite

(huo le daliang de yeyu shijian beisong shi shishi

spend ASP much Mod spare time learning by heart is fact ),

despite

(beisong de guocheng xiangdang jiannan

learning by heart Mod process rather difficult)_, I managed to stick to doing this.

${ }^{\text {vi }}$ Different from purely formulaic expressions (e.g. How do you do?), this type of chunks have 'slots' which can take different words according to the situation. Take despite the fact that for example, 'fact' can be replaced by 'idea', 'danger' and so on. Other terms for these sequences include 'productive speech formula' (Nattinger \& DeCarrico, 1992), 'slot-and-frame pattern' (N. Ellis, 2003), ‘semi-fixed grammatical pattern' (Taguchi, 2007).

vii It seems that Robinson's 'incidental condition' theory may not hold true for all learners due to ignoring local factors. I 
would argue for the need to discriminate between learners immersed in drastically different learning contexts.

viii According to Johnson (1996), L2 development is simultaneously a knowledge-building process and a process whereby L2 learners learn to develop control over use of knowledge under various real operation conditions.

${ }^{\text {ix }}$ A recognised tendency among Chinese students is 'the enthusiasm for grammar'(Wen \& Clement, 2003: 23). To Chinese learners of English, as a Chinese scholar put it, 'every phenomenon in language must come to grammar for its final judgement. A great satisfaction is felt in sentences that can be logically explained and justified by grammar' (Ding, 1987: 54).

${ }^{\mathrm{x}}$ The university was a national key university, the minimum required score for admission was higher than ordinary universities.

${ }^{x i}$ There are two aspects of complexity: vocabulary and syntax. For example, 'take in' was a new phrase for the participants in the study. Syntactically, the passive voice of gerund following 'warned me against' can be a challenge for Chinese students due to contrastive differences of syntax between Chinese and English.

xii The freshmen registering in 2007 at the university were divided into two levels: while only one tenth of the students in each school were singled out to be placed in a low-advanced class, the remaining ones were grouped into lowintermediate classes.

xiii The paragraph assigned to MG2 was one of the three paragraphs which were suggested for learning by heart in a regular after-class task, set out in each unit of the course book. From my teaching experience, a small number of students might memorise those paragraphs as a way to prepare the final examination as it is a tradition in this university that there is a section testing students' memorization of those paragraphs required in the course book in the written test of the final examination.

${ }^{\text {xiv }}$ One might argue that the single-item test seems risky as well as the chance results from the multiple-choice. I hasten to point out, however, the potential risk is offset to some extent by the reasonably big number of the participants (104) and the supplement of qualitative data elicited from subsequent interviews.

${ }^{\mathrm{xv}}$ The fast reading exercise was also performed with the other two groups in regular class time as a planed activity of the teacher. I intervened in the regular activity only in terms of providing the reading material for research purpose.

${ }^{\mathrm{xvi}}$ According to a questionnaire attached to the recitation test, the overwhelming majority in the memorization groups spent about 15 minutes finishing the assignment, the longest time spent being 20 minutes and the shortest ten minutes. An anonymous reviewer commented that the learning-by-heart method is likely to involve much less time on the specific target form. I argue that the actual time period the participants invested on the memorization assignments might be longer than that reported in order to pass the recitation test (i.e. write down the paragraph verbatim from memory). Moreover, many of them were observed to be still working on the task immediately before the recitation test (the score of which was believed to have impact on their grades on daily performance).

${ }^{x v i i}$ While the answers starting with the fact that and it is a fact that are rather straightforward to apply the rule, an anonymous reviewer questioned the applicability to other two answers as it is possible that the learners may fail to infer that Despite everything I've learned is an instance of the same grammatical structure as Despite my friend's warning against being taken in or that Despite I've learned everything is wrong in the same way that Despite my friend warned me against being taken in is. Although I agree with the reviewer here, my analysis showed no case of inconsistent choices on these two items.

${ }^{x v i i i}$ The reason why IG outperformed MGs in the multiple-choice test but did worse in the translation test can be that the grammar points presented in a decontextualized manner (e.g. explicit grammar explanation) may be remembered in similar contexts, such as a discrete-point grammar test (in this case, multiple-choice test), but difficult to retrieve in a communicative context (in this case, translation test, which may demand more attention on meanings than forms) (Lightbown, 2008). Although the performance of IG is not the focus of current study, only serving as a contrast for any effect or change observed in memorization groups (as was already stated in 3.2), it needs to be pointed out that the remarkable increase of the performance of the IG on the multiple-choice test confirms the findings of previous studies indicating that form-focused instruction can improve post-instruction awareness of morphology or syntax in L2. For instance, one study (Scott, 1989) produced evidence that explicit teaching results in improved recall and production on tests targeted to the grammar points in question and another (White, 1991) provided documentation that teaching particular points can result in statistically measurable improvement in the short run. It also replicates the finding produced by the first-stage study (Yu, 2009) of the research.

${ }^{\text {xix }}$ Compare the exemplar enforced upon MG1 (i.e. Despite her worries, ... despite the fact that Oprah was good at her job.) with that memorised by MG2 (i.e. Despite the fact that my friend warned me against being taken in, despite everything I've learned, .....)

${ }^{\mathrm{xx}}$ In investigating the effect of explicit instruction for subjects learning Welsh morphology, Ellis found that the subjects who have both 'rules and instances' outperformed the 'random' learners given only examples and the 'rule' learners given only rules. 